\title{
Assessment of the Indigenous Knowledge and Use of Traditional Medicinal Plants in Wolaita Zone, Southern Ethiopia
}

\author{
Asfaw Tora ${ }^{a^{*}}$, Tarekegn Heliso ${ }^{b}$ \\ ${ }^{a *}$ Wolaita Sodo University, Department of Biology, SNNPR, Sodo, Postcode:138, Ethiopia. \\ ${ }^{\mathrm{b}}$ Wolaita Sodo University, Department of Chemistry, Sodo, and 138, Ethiopia.
}

\begin{abstract}
Plants have traditionally been used as a source of medicine in Ethiopia by indigenous people of different ethnic groups. The Wolaita Zone is one of these where such practice is very common and the associated indigenous knowledge has not been studied and documented well. So this study is aimed at assessing the indigenous knowledge and use of traditional medicinal plants in some weredas of the zone. The knowledge and use of medicinal plant species by traditional healers was investigated in Daamot Pulasa, Damot Woyde, Humbo and Sodo Zuria, Wolaita Zone, Southern Ethiopia from May, 2012 to September, 2012. Traditional healers of the study area were selected purposefully with the help of local administrators and local elderly people and interviewed with the help of translators to gather information on the knowledge and use of medicinal plants used as a remedy for human ailments in the study area. In the current study, it was reported that 62 plant species belonging to 62 genera and 36 families were commonly used to treat 30 human ailments. Most of these species were wild and harvested mainly for their leaves (60.5\%). The most cited traditional medicinal plant species was of Asteraceae family. No significant correlation was observed between the age, gender and educational status of traditional healers with the number of species reported and the indigenous knowledge transfer was found to be similar.
\end{abstract}

Keywords: Indigenous knowledge, medicinal plants, traditional healers

\section{INTRODUCTION}

\subsection{Background of the Study}

Traditional medicines include herbal medicines composed of herbs, herbal materials, herbal preparations, and finished herbal products, that contain as active ingredients parts of plants, or other plant materials, or combinations thereof. Traditional medicines may also use animal parts and/or minerals (WHO, 2002-2005). It is estimated that at least 25\% of all modern medicines are derived, either directly or indirectly, from medicinal plants, primarily through the application of modern technology to traditional knowledge. In the case of certain classes of pharmaceuticals, such as antitumor and antimicrobial medicines, this percentage may be as high as 60\% (WHO, 2004.). Between $70 \%$ and $95 \%$ of citizens in a majority of developing countries, especially those in Asia, Africa, Latin America and the Middle East, use traditional medicine, including traditional and herbal medicines, for the management of health and as primary health care to address their health-care needs and concerns (WHO, 2002-2005). Traditional medicines have always played a key role in world health and continue to be used to treat a vast array of conditions and complaints. A survey completed by WHO's Roll Back Malaria programme showed that in Ghana, Mali, Nigeria and Zambia, around $60 \%$ of all febrile cases in children, presumably due to malaria, are treated at home with herbal medicine (WHO, 2002-2005). Other conditions commonly addressed with traditional medicines include digestive or intestinal diseases, sickle-cell anaemia, hypertension, high cholesterol, headaches, insomnia, diarrhea, microbial infections, bronchitis, diabetes, burns, rashes and menopause (Ankobonggo, 1992).

In Ethiopia, plants have been used as a source of medicine from time immemorial to treat different ailments. Traditional medicine has become an integral part of the culture. About $80 \%$ of Ethiopians depends on traditional medicine for health care and more than $95 \%$ of traditional medicinal preparations is of plant origin. Over $85 \%$ of rural population and an increasing number of poor people 
in urban centers derive their livelihood from collection and trade of medicinal plant material. According to recent studies, it is estimated that there are more than 7000 species of flowering plants recorded in Ethiopia, of which $12 \%$ or more are probably endemic. Medicinal plants comprise one of the important components of the vegetation. On record there are 600 species of medicinal plants constituting a little over 10 percent of Ethiopia's vascular flora. They are distributed all over the country, with greater concentration in the south and southwestern part of the country (EC-FAO, 1998).

Of all forms of indigenous knowledge, knowledge about plant use, and particularly medicinal plant use, appears to be one of the most vulnerable to loss. This loss of plant knowledge has been attributed to many factors including logging (Shanley and Rosa, 2004), expansion of markets, globalization and amalgamation of cultures, and other human population pressures (Sheldon et al. 1997). In recent years, medicinal plant usage has been reduced and is no longer held in overarching cultural applications; the formal occupation of herbal practitioner is disappearing. This loss has serious health implications as approximately $80 \%$ of the developing world relies on traditional medicines primarily derived from plants (Farnsworth, 1988).

Much of the knowledge on traditional medicinal plants in most cases is available in rural communities and mostly perpetuated by word of mouth within families and small communities in Ethiopia, which is a general truth in all-rural Africa (Eyssartier, 2008). Ethnobotanical knowledge is transferred, often orally or through practice, along information networks (Alcorn, 1995). Plant knowledge is typically transmitted to younger generations from older relatives. When plant knowledge is passed orally, as is often the case in non-literate societies, the society may eventually reach a limit to the amount of information able to be stored in memory (a type of 'mental economy') (Balée, 1994). This makes orally transmitted knowledge most susceptible to rapid changes (Grenier, 1998). It is therefore best to combine oral transmission with action or hands-on experience (Ohmagari and Berkes, 1997).

Most of the research works done on traditional medicine in southern Ethiopia were on areas of south west and almost nothing has been done around Wolaita Zone. Thus, this study is intended to document the indigenous knowledge on the use of traditional medicinal plants by the local people in some of the Woredas of Wolaita zone.

\section{OBJECTIVES OF THE STUDY}

\subsection{General Objective}

The main objective of this study is to assess and document indigenous knowledge of the society on medicinal plants and their use in some weredas of Wolaita Zone, Southern Ethiopia.

\subsection{Specific Objectives}

2.2.1 To assess the indigenous knowledge of the people on use of medicinal plants in study area.

2.2.2 To assess and identify plant species that are used as medicines for the treatment of human health problems.

2.2.3 To identify the plant parts used in the preparation of remedies.

\section{Materials AND Methods}

\subsection{Study Area}

The study was conducted in four weredas of Wolaita zone; Damot Fulasa, Damot Woyde, Humbo and Sodo Zuria. Wolaitta is located at $350 \mathrm{~km}$. south of the capital, between $6^{\circ} 40^{\prime \prime}$ and $7^{\circ} 58^{\prime \prime} \mathrm{N}$ Latitude and $37^{\circ} 14^{\prime \prime}$ and $37^{\circ} 56^{\prime \prime}$ E Longitude. With a total area of 438,370 hectares, Wolaitta is inhabited by over 1.7 million people. The Wolaita people are one of the indigenous people of Ethiopia who have their own culture, tradition, political legacy and kingdom. The major economic activities are agriculture (production of legumes, root crops and some cereals), and livestock rearing. The study areas lie at an altitudinal range of $1500-2500$ m.a.s.l. and have agro ecologies of dega (highland), woynadega (mid altitude) and kola (low land) with a mean annual temperature of $17.5^{\circ} \mathrm{C}$ and annual rainfall that varies from $800-1400 \mathrm{~mm}$ according to the projected CSA final report of 2007 (fig.1). 
Assessment of the Indigenous Knowledge and Use of Traditional Medicinal Plants in Wolaita Zone, Southern Ethiopia

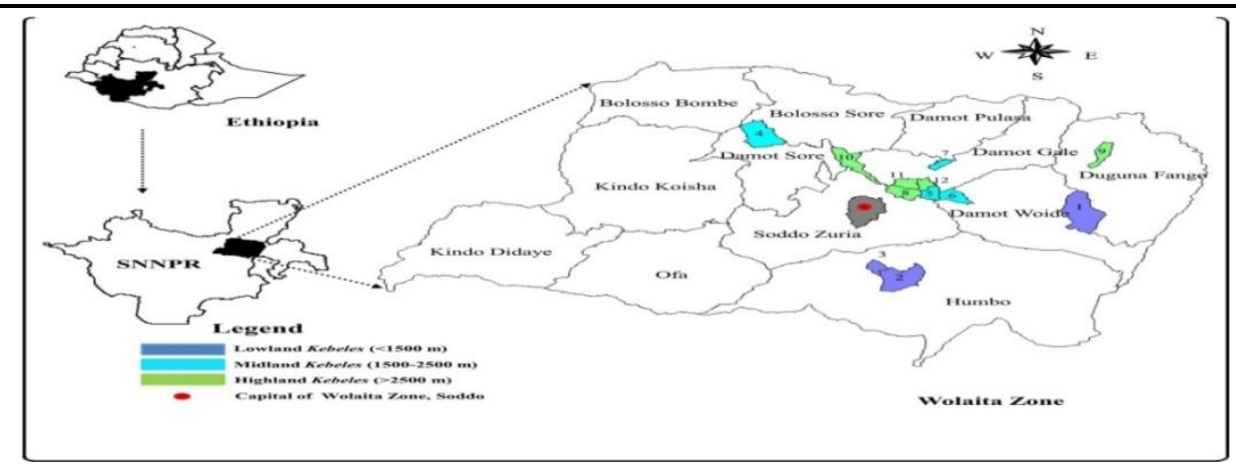

Figure1. Map of the study area

\subsection{Selection of study sites}

The study was conducted in 20 kebeles in the four Woredas of Wolaita Zone, SNNPR from May 2012 to September 2012. The study sites were selected based on availability of traditional healers identified with the assistance of local authorities.

\subsection{Data Collection}

Semi-structured interviewees, observation and guided field visits with informants were employed to obtain ethnobotanical data. For this study purposive sampling was employed to identify potential informants. Accordingly, a total of 30 informants were selected purposefully with the help of local administrators and local elderly people from four weredas of Wolaita Zone. Recommended traditional medicine practitioners were identified as potential informants and subsequently participated in personal interviews. Interviews were based on a checklist of questions prepared beforehand in English and translated to the local language (Wolaitigna).

Identification of the medicinal plant specimens collected from the study area was performed at the National Herbarium of Ethiopia, Addis Ababa University using taxonomic keys and Floras and by comparison with already identified herbarium specimens. The identified specimens were deposited at the National Herbarium.

\subsection{Data analysis}

Descriptive statistics was used to analyze the ethnobotanical data. Spearman correlation test was run in SPSS 16.0 to analyze ethnobotanical data. The spearman correlation test was used to determine the correlation of the indigenous plant use knowledge with the age of traditional healers, their educational level and gender. MS Excel Spreadsheet was also utilized for drawing bar graphs and to determine proportions.

\section{RESULTS}

A total of 62 medicinal plant species from 36 families and 62 genera are used for treating about 30 health problems were identified in the survey. Most of these species were wild and harvested for their leaves (60.5\%). With regard to the remedies, they were administered mainly through oral, dermal, nasal routes. The family Asteraceae was represented by 8 species followed by Lamaceae (6), Solanaceae (5), Euphorbiaceae (5), Poaceae (4), Fabaceae (3) and other families with insignificant frequency.

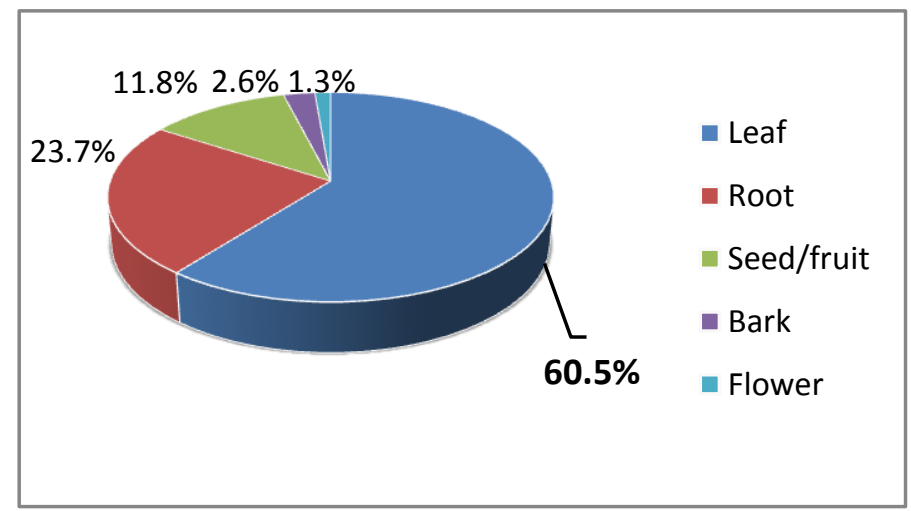

Figure2. Parts of plants used in the prepartion of remedies 
According to the assessment data of the questionnaire on the indigenous knowledge of traditional medicinal plants in the 20 kebeles of the four weredas most of the respondents were illiterate and gender wise $52 \%$ are male and $48 \%$ are females. The age distribution of the respondents is observed that $36 \%$ are in the age range $20-40,36 \%$ are in $41-60$ and $28 \%$ are above 61 . Traditional healers of the study area were found to play great roles in the primary healthcare systems of the local people as they were treating resource poor people who had little access and couldn't afford the cost for modern medications. They also reported that the local people have been seeking for their treatment even in preference to modern medications and also in connection with the community's belief that they would not get better medications for some of the diseases in modern health services.

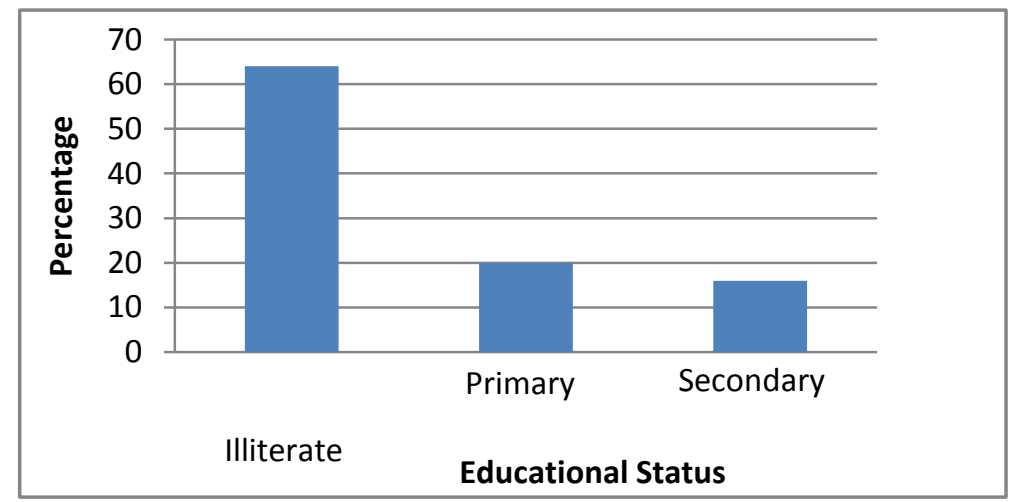

Figure2. Educational status of traditional healers

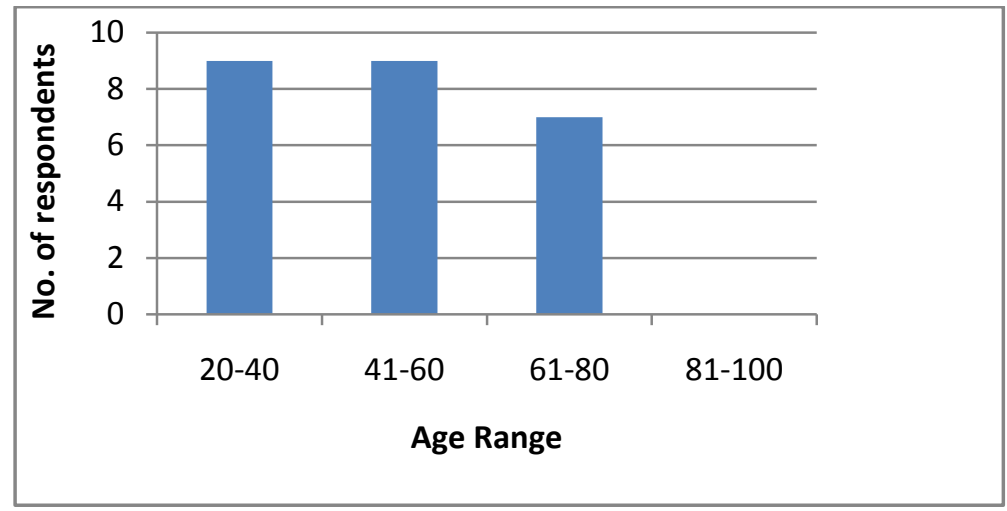

Figure3. Age distribution of traditional healers

No significant (Spearman correlation test, $r=-0.213, \alpha=0.05, p=0.307$ ) correlation was observed between the age of traditional healers and the number of species reported by the healers. And also no significant (Spearman correlation test, $\mathrm{r}=0.184, \alpha=0.05, \mathrm{p}=0.006$ ) correlation was observed between the gender of traditional healers and the number of species reported by the healers. Moreover, the Spearman correlation test did not demonstrate significant (Spearman correlation test, $r$ $=0.083, \alpha=0.05, p=0.693$ ) correlation between the educational level of traditional healers and the number of species reported. The response of the traditional healers with regard to their indigenous knowledge transfer was similar in that some of them reported to transfer it to selected family members while some did not transfer it at all.

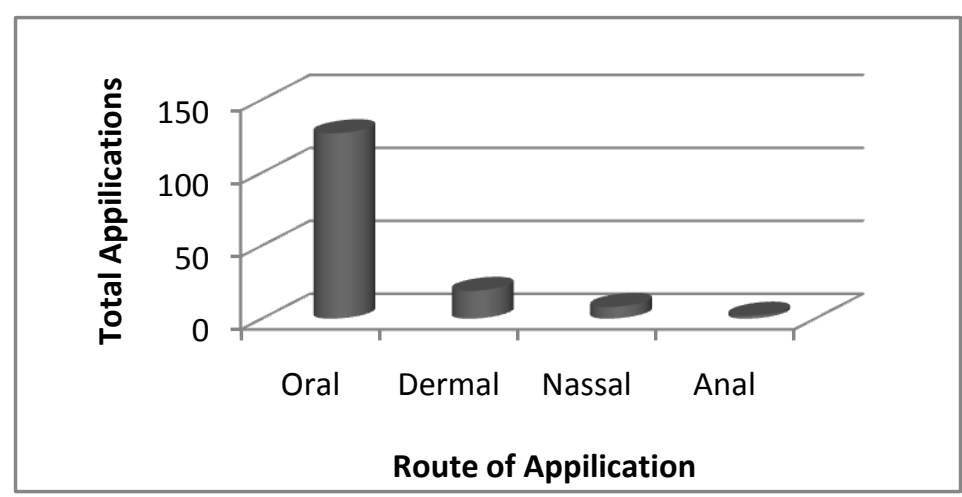

Figure4. Route of application 
Remedies for the different health problems were prepared from leaves $(60.5 \%)$, root $(23.7 \%)$, seed or fruit $(11.8 \%)$, flower $(1.3 \%)$ and bark $(2.6 \%)$. These remedies were reported to be administered mainly through oral, dermal, nasal and anal routes. The most cited modes of remedy applications were drinking, topical applications and dropping.

\section{DisCUSSION}

The use of traditional medicinal plants to treat human ailments in these areas is not documented and research has not been done before in this regard as to our knowledge. Most of such researches are concentrated in south west part of the SNNP region. Our findings show that there is an important intracultural variation of medicinal plant knowledge in terms of the number of plants known at all study sites, but no clear patterns could be identified to explain this variation.

The indigenous knowledge trend shows that among the practionors in the society is transmitted orally from elders but based on the data currently no clear pattern is observed as to how the knowledge is transferred.

Based on the result obtained after the survey on the study areas; Damot Pulasa, Damot Woyde, Humbo and Sodo Zuria, Damot Pulasa has got the most various types of medicinal plant species.

Most of the medicinal plant species used were reported as wild. Similar studies conducted and reported in literatures indicated that most medicinal plant species used to treat human ailments were wild. This implies that the majority of plants of medical importance were not yet cultivated by traditional healers.

Leaves were the most cited plant parts used by the healers for the preparation of traditional medicines and this finding is in line with the results of other ethno medicinal studies. Remedies were commonly prepared together with some additives like milk, coffee and tea and consequently the most common route of application of these remedies is oral as indicated on the bar graph.

\section{CONCLUSION AND RECOMMENDATIONS}

In the present study, sixty two plant species of medicinal importance were recorded and documented. The majority of the reported medicinal plant species were wild. This shows that there is a need to create awareness among the practitioners and the society in general about the management of traditional medicinal plants so that they can benefit by cultivating on gardens to generate income. The study result does not clearly show as to how the indigenous knowledge associated with traditional medicinal plants correlates with the age, gender and educational status of traditional healers of the areas. So it implies that a further and broad study in all wered as of the Wolaita Zone is needed. There were interesting medicinal plant species on which further phytochemical investigation can be done in the future.

\section{ACKNOWLEDGEMENTS}

Authors are grateful to the local people of Wolaita for their hospitality and kind responses to our inquiries on information about their indigenous knowledge on assessment of medicinal plant; Wolaita Sodo University for financial, material and other facilities.

\section{REFERENCES}

Abebe Demisse (2001). Biodiversity conservation of medicinal plants: Problem and prospects. In: Conservation and sustainable use of medicinal plants in Ethiopia Proceeding of The National Workshop on Biodiversity, Conservation and Sustainable Use of Medicinal Plants in Ethiopia, 28 April-01 May 1998, pp.198-203.(Medhin Zewdu and Abebe Demissie eds.). IBCR, AA.

Zemede Asfaw (2001). The role of home gardens in production and conservation of medicinal plants. In: Proceedings of the National Workshop on Biodiversity Conservation and Sustainable Use of Medicinal Plants in Ethiopia, pp. 76-91 (Medhin Zewdu and Abebe Demissie eds.). IBCR, Addis Ababa, Ethiopia.

Pankhurst, R. (2001). The status and availability of oral and written knowledge on traditional health care. In: Conservation and Sustainable Use of Medicinal Plants in Ethiopia Proceeding of The National Workshop on Biodiversity Conservation and Sustainable Use of Medicinal Plants in Ethiopia, 28 April-01 May 1998, pp.92-106 (Medhin Zewdu and Abebe Demissie eds.). IBCR, AA. 
Tesfaye Hailemariam Bekalo, Sebsebe Demissew Woodmatas and Zemede Asfaw Woldemariam (2009). An ethnobotanical study of medicinal plants used by local people in the lowlands of Konta Special Woreda, southern nations, nationalities and peoples regional state, Ethiopia: Journal of Ethnobiology and Ethnomedicine,5:26.

Zenebe, G. Zerihun, M. \& Solomon, Z. (2012). An Ethnobotanical Study of Medicinal Plants in Asgede Tsimbila District, Northwestern Tigray, Northern Ethiopia, Ethnobotany Research \& Applications 10:305-320.

Semali, L.M. and Kincheloe, J.L. (1999). What is Indigenous Knowledge? Voices from the Academy. Falmer Press, New York.

Abbink, J. (1995). Medicinal and ritual plants of the Ethiopian Southwest: an account of recent research. Indigenous knowledge and Development Monitor, 3:6-8.

Mirutse, G. (1999). An Ethno-botanical study of Medicinal Plants Used by the People in Ethiopia. M. Sc. Thesis, Uppsala, Sweden.

Mesfin, F. (2007). An ethnobotanical study of medicinal plants in Wonago woreda, SNNPR, Ethiopia. M.Sc. thesis, Addis Ababa University, Ethiopia.

Dawit, A. (1986). Traditional medicine in Ethiopia.The attempt being made to promote it for effective and better utilization. SINET: Ethiopian Journal of Scince9, 61-69. Addis Ababa, Ethiopia.

Fassil, K. (2001). The status and availability of oral and written knowledge on traditional health care in Ethiopia. In: Medhin Z, Abebe D (eds.). Conservation and Sustainable Use of Medicinal plants in Ethiopia. Proceeding of the National workshop on Biodiversity Conservation and Sustainable use of medicinal plants in Ethiopia, 28 April- 01 May 1998, IBCR, Addis Ababa pp. 107-119.

Sofowora, A. (1982). Medicinal plants and Traditional medicine in Africa. John Wiley and Sons. New York. Pp. 255-256.

FAO. Some medicinal forest plants of Africa and Latin America. FAO, UN, Rome,1986; 1-253.

Sani, H. Dambatta and Aliyu, B.S (2011). A survey of major ethno medicinal plants of kano north, Nigeria, their knowledge and uses by traditional healers. Bayero Journal of Pure and Applied Sciences, Bajopas Volume 4 Number 2 December.

Shanker, D. (1993). Medicinal Plants and Biodiversities. Journal of Ethiopharmacology.33: 100-119.

Hamilton, A. C. (2003). Medicinal Plants and Conservation: issues and approaches.International plant conservation unit, WWF-UK, Pandahouse, Catteshall Lane, UK.51pp.

Parrota, J. A. (2002). Restoration and Management of Degraded Tropical Forest Landscapes.In: Modern Trends in Applied Terrestrial Ecology. (R.S., Ambashet and N.K., Ambasheteds.) pp. 135-148.

Cunningham, A. B. (1993). African Medicinal Plants: Setting priorities at the interface healthcare between conservation and primary health care. (Sample, A. ed.). People and plants working paper, pp. 1-50. Paris, UNESCO.

WHO Traditional medicine strategy 2002-2005.Geneva, World Health Organization, 2002 (WHO/EDM/TRM/2002.1). Available at: http://apps.who.int/medicinedocs/en/d/Js2297e/

Sucher, N. J., \& Carles, M. C. (2008). Genome-based approaches to the authentication of medicinal plants. Planta Medica, 74(6): 603-623.

Calixto, J. B. (2000). Efficacy, safety, quality control, marketing and regulatory guidelines for herbal medicines (phytotherapeutic agents). Brazilian Journal of Medicine and Biological Research, 33:179-189.

Guidelines on registration of traditional medicines in the WHO African Region. Brazzaville, World Health Organization Regional Office for Africa, 2004. (AFR/TRM/04.1). Available at: http://whqlibdoc.who.int/afro/2004/AFR_TRM_04.1.pdf

AIDS Epidemic Update: December 2003. Geneva, Joint United Nations Programme on HIV/AIDS, 2003. Available at: http://data.unaids.org/publications/irc-pub06/jc943-epiupdate2003_en.pdf

Zhang, X. (2008). Unpublished data, World Health Organization.

Goldbeck-Wood, S., Dorozynski, A. \& Lie, L.G. (1996). Complementary medicine is booming worldwide. British Medical Journal, 313 (7050): 131-133.

Kaptchuk, T., Eisenberg, D.M. (1998). The persuasive appeal of alternative medicine. Annals of Internal Medicine, 129:1061-1065. 
Assessment of the Indigenous Knowledge and Use of Traditional Medicinal Plants in Wolaita Zone, Southern Ethiopia

AUTHORS' BIOGRAPHY

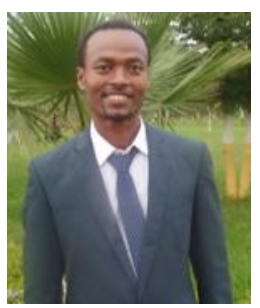

Asfaw Tora Kacho, Lecturer at Wolaita Sodo University Department of Biology, College of Natural and Computational Sciences, Sodo, Ethiopia

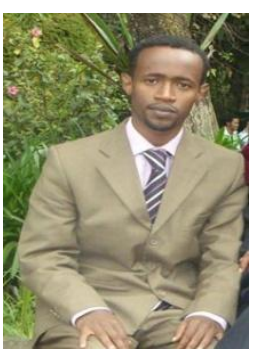

Tarekegn Heliso, Lecturer at Wolaita Sodo University Department of Chemistry, College of Natural and Computational Sciences, Sodo, Ethiopia 